\title{
In Vitro Experimental Study: Comparison of Tooth Fissure Morphology Patterns Various the Adaptability of two Fissure Sealants
}

Dr. Saurabh Satyarth (MDS) ${ }^{*}$, Dr. Bhawna Kumari (MDS)

Department of Dentistry, Government Medical College \& Hospital, Bettiah, Bihar India

DOI: $\underline{10.36347 / \text { sjds.2020.v07i11.001 }}$

| Received: 05.10.2020 | Accepted: 29.10.2020 | Published: 11.11.2020

*Corresponding author: Dr. Saurabh Satyarth

Abstract

Original Research Article

Background: This study has conducted for compare the adaptation of resin-based sealants with that of Resin modified glass ionome-based sealants in various tooth fissure morphologies. Methods: It"s an in vitro experimental study done at department of dentistry, Government Medical College \& Hospital, Bettiah (Bihar). Ten extracted human molars were randomly assigned for two groups, $(n=5)$ each. Fissure sealant material (Resin based sealant or resin modified glass ionomer-based sealant) has applied on the occlusal surface of the tooth according to manufacturer's recommendations. Specimens were thermocycled and then sectioned into three longitudinal parts in the bucco- lingual direction. Specimens were examined using scanning electron microscope for the adaptation of the sealant in the occlusal fissure. Mann-Whitney $-U$ test and Kruskall-Wallis test were applied to compare the adaptability scores of sealant materials in the tooth fissure. Level of significance was kept at 0.05.Results: There was no significant difference in the adaptability scores among $\mathrm{U}$-shaped ( $p$-value $=0.35), \mathrm{V}$-shaped $(p$-value $=0.89), \mathrm{IK}$-shaped $(p$ value $=0.52)$, I-shaped $(p$-value- $=0.41)$ and $Y$-shaped $(p$-value $=1.00)$ fissure patterns. Similarly, there were no significant differences observed between the resin-based sealant $(p$-value $=0.95)$ versus RMGIC based sealant $(p$ value $=0.63$ ) for the adaptability scores in various tooth fissure morphologies. Conclusions: No significant difference was found between resin-based sealants and resin modified glass ionomer-based sealants for the adaptation in various tooth fissure patterns.

Keywords: Fissure morphology; Fissure sealants; RMGIC; Flowable resin; Scanning electron microscopy.

Copyright $(\mathcal{C} 2020$ The Author(s): This is an open-access article distributed under the terms of the Creative Commons Attribution 4.0 International License (CC BY-NC 4.0) which permits unrestricted use, distribution, and reproduction in any medium for non-commercial use provided the original author and source are credited.

\section{INTRODUCTION}

These fissures are the anatomic imperfections present on occlusal surface of teeth that represent the embryological coalescence of developing enamel lobes. Geometrically, the base of the fissure is the location where bacterial carious activity initiates. On the basis of morphology, molar fissures are classified into five types. These shapes are "U, V, I, Y and IK $[1,2]$ ". The reported prevalence of the sub-types of these fissures is following: "V-type (34\%), IK-type (26\%), I-type (19\%), U-type (14\%), Inverted Y-type (7\%)[1]". As the fissures are narrow in shape, they readily get occupied by the food debris and bacterial colonies [3, 4]. Therefore, sealing them to early as possible is advisable to prevent initiation of dental caries [3].

Sealants are notonly used in for primary prevention but also helpful in the secondary prevention for dental caries. Adaptability of the sealants is an important factor that contributes towards its retention in the tooth and resistance against dental caries [1]. The objective of this study was to assess the adaptation of the two common varieties of sealants and to assess the effect of various fissure morphologies on the adaptation of the sealant material.

It was speculated that the retention of sealants will be vary in different fissure morphologies. Similarly, the adaptability of resin-based sealants would be different than the resin modified glass ionomerbased sealants in various tooth morphology pattern.

\section{OBJECTIVE}

To compare the adaptation of resin-based sealants with that of resin modified glass ionomer-based sealants in various tooth fissure morphologies.

\section{MATERIAL AND METHODS}

It was an in vitro experimental study conducted in September 2018 to July 2019 at the department of dentistry, Government Medical College \& Hospital, Bettiah (Bihar). 
Study inclusion criteria were non-carious human extracted upper and lower third molars $(n=10)$. The teeth were collected from oral surgery clinics, department of dentistry, Government Medical College \& Hospital, Bettiah(Bihar). Informed consent was taken from the subjects who donated their teeth to be used the study purpose. These teeth were already due for extraction for pericoronitis. Teeth with caries, fractures, enamel cracks, restorations, attrition, erosion or any pathology such as congenital malformations were excluded.

After extraction, teeth were cleaned by using tap water followed by treatment with pumice slurry along with a dental rubber cup. After that, they were stored in distilled water at $4{ }^{\circ} \mathrm{C}$. Teeth were randomly allocated (using lottery method) into two groups comprising of five teeth (5) each. Group A was treated with Filtek flow (Flowable Resin, 3M-ESPE, USA) whereas group B was subjected to Vitremer (Resin modified glass ionomer, 3M-ESPE, USA). Specimens were etched with $37 \%$ phosphoric acid gel (Dentsply, USA), rinsed with air/water spray for 20 seconds and with oil-free compressed air. The sealant materials were placed according to the manufacturer's guidelines.

For Group A: Single Bond (3M/ESPE) adhesive system was applied, air-thinned and lightcured (Blue Dent LED, Power Smart, China) for 10 seconds. Then the Filtek flow sealant material was applied onto the primed pits and fissures along the entire extension with an explorer followed by lightcured (Blue Dent LED, Power Smart, China) for 20 seconds.

For Group B: Vitremer primer was applied and left in place for 30 seconds, air-thinned and light-cured (Blue Dent LED, Power Smart, China) for 20 seconds. Powder and liquid of the sealant material were mixed in ration of 1: to obtain a low viscosity mix that could be flown easily into the fissures. The sealant material was applied onto the pits and fissures with the Compule tip gun (Dentsply, USA) and light-cured for 40 seconds. Vitremer finishing gloss was applied and light-cured (Blue Dent LED, Power Smart, China) for 20 seconds.

Specimens were thermocycled in controlled Digital Water Bath (Human Lab Instrument Co, Korea) for 250 cycles at temperatures of $4{ }^{\circ} \mathrm{C} \pm 2{ }^{\circ} \mathrm{C}, 37^{\circ} \mathrm{C} \pm 2$ ${ }^{\circ} \mathrm{C}$ and $60{ }^{\circ} \mathrm{C} \pm 2{ }^{\circ} \mathrm{C}$ with dwell time of 30 seconds. Thermocycling was done to simulate various temperatures which are usually encountered in real life conditions.

All teeth were decoronated at cemento-enamel junction and roots were discarded. The crowns were then embedded in a self-curing epoxy resin in a rubber mould of $3 \times 4 \times 4 \mathrm{~cm}$ volume. Crown portion was further sectioned into three parts in longitudinal dimension using a diamond cutting saw (EQ MT 4, MTI
Corporation, USA) with a blade of $0.5 \mathrm{~mm}$ thickness at the speed of $2000 \mathrm{rpm}$. This resulted in four surfaces for inspection for each crown. In this manner, a total of

$10 \times 4=40$ specimens were made. These specimens were exposed to sunlight for 24 hours so that they could be dried before gold sputtering.

The sample slides were mounted on aluminum stubs with squash tape and were sputter coated with gold-palladium in JEOL JFC - 1500 Auto-fine coater for 120 seconds. This is done to change the non-conducting specimens into conductors. These sample slides were then placed in a special aluminum tray, in the vacuum chamber of the Scanning Electron Microscope (SEM). The sample slides were then examined with an Analytical Scanning Electron Microscope (JEOL JSM 6380LA, Japan) a using magnification of 20X-50X at acceleration voltage of $5 \mathrm{kV}$. The structure were analyzed and observed on the screen (Figure-1).

The assessment was done using an ordinal scale scoring criteria mentioned below [7]:

$1=$ complete adaptation to all fissures as good

$2=$ one interface failure of adaptation as acceptable

$3=$ more than one interface failure of adaptation as poor

Data were analyzed by using SPSS version 16.0.

Descriptive statistics for adaptability scores of molar fissures morphology of subtypes/subgroups in the two sealants type (Flowable Resin and RMGIC) were reported as median and interquartile range (IQR). Mann-Whitney $U$ test was used to examine the differences of adaptability score in two groups (Flowable Resin and RMGIC). Kruskal-Wallis test were applied to test whether there were significant differences in the adaptability scores of fissure morphology subtypes within the sealant groups. A $p$ value of $<0.05$ was considered as statistically significant.

\section{RESULTS}

Out of 37 specimens, one was discarded due to procedural errors. A total of 37 specimen slides were included in the study. Of these, 18 samples had flowable resin sealant while 19 sample specimens had RMGIC based sealant. The distribution of adaptability scores of Flowable resin and RMGIC sealants with respect to sub-types of fissures morphology is shown in table 1. The median and interquartile range (IQR) of adaptability score in U-shape was 1 (2.5) in Flowable resin group and $1(0)$ in RMGIC group while the median and inter-quartile range of adaptability scores in V-shape was 1 (1) both groups.

Not significant differences in adaptability scores were observed among U-shaped ( $p$-value $=0.35$ ), $\mathrm{V}$-shaped $(p$-value $=0.89), \mathrm{IK}$-shaped $(p$-value $=0.52), \mathrm{I}$ shaped $(p$-value $=0.41)$ and Y-shaped $(p$-value $=1.00)$ 
fissure morphologies for the two varieties of sealant materials.
Similarly, there was no significant differences observed within the sealant groups Flowable resin $(p$ value $=0.95)$ and $\mathrm{RMGIC}$ ( $p$-value $=0.63)$ for various fissure morphology patterns (Table-2).

Table-1: Comparison of Adaptability Scores distribution (1 to 3 score) between flowable resin and RMGIC groups $(\mathbf{n = 3 9})$ under SEM

\begin{tabular}{|c|c|c|c|c|c|c|c|c|}
\hline \multirow{4}{*}{$\begin{array}{c}\text { Fissure } \\
\text { morphology }\end{array}$} & \multirow{2}{*}{\multicolumn{2}{|c|}{$\begin{array}{c}\text { Flowable Resin } \\
\mathrm{n}=19\end{array}$}} & & & & \multicolumn{2}{|c|}{ RMGIC } & \multirow[b]{4}{*}{$\mathbf{n}$} \\
\hline & & & & & & \multirow{2}{*}{\multicolumn{2}{|c|}{$\begin{array}{l}\mathbf{n = 2 0} \\
\text { Score }\end{array}$}} & \\
\hline & \multicolumn{2}{|c|}{ Score } & & & & & & \\
\hline & 1 & 2 & 3 & $\mathbf{n}$ & 1 & 2 & 3 & \\
\hline U shaped & 3 & 1 & 1 & 5 & 5 & 1 & 0 & 6 \\
\hline V shaped & 5 & 1 & 1 & 7 & 6 & 2 & 1 & 9 \\
\hline Ik shaped & 2 & 1 & 0 & 3 & 1 & 0 & 1 & 2 \\
\hline I shaped & 2 & 0 & 1 & 3 & 2 & 0 & 0 & 2 \\
\hline Y shaped & 1 & 0 & 0 & 1 & 1 & 0 & 0 & 1 \\
\hline Total n & 13 & 3 & 3 & 19 & 15 & 3 & 2 & 20 \\
\hline
\end{tabular}

RMGIC: Resin modified glass ionomer-based sealant. SEM: Scanning electron microscopy. Sealant adaptability Scores were done on an ordinal scale where
1 refers to excellent, 2 refers to acceptable and 3 refers to poor adaptability of sealant material into the fissure morphology

Table-2: Comparison of median adaptability score of flowable resin and RMGIC based sealants $(\mathrm{n}=39)$

\begin{tabular}{|c|c|c|c|}
\hline $\begin{array}{l}\text { Fissure } \\
\text { morphology }\end{array}$ & Flowable Resin Group & RMGIC Group & $p-$ value $*$ \\
\hline & $n=19$ & $\mathbf{n}=\mathbf{2 0}$ & \\
\hline & Median (IQR) & Median (IQR) & \\
\hline U Shaped & $1(2)$ & $1(0)$ & 0.35 \\
\hline V Shaped & $1(1)$ & $1(1)$ & 0.89 \\
\hline Ik Shaped & $1(-)$ & $2(-)$ & 0.52 \\
\hline I Shaped & $1(-)$ & $2(-)$ & 0.41 \\
\hline Y Shaped & $1(-)$ & $1(-)$ & 1.00 \\
\hline$p$-value** & 0.95 & 0.63 & \\
\hline$* p$-value & $\begin{array}{l}\text { Calculated by using Mann-Whitney } \\
\text { U test. }\end{array}$ & $\begin{array}{l}* * p \text {-value calculated by using } \\
\text { Kruskal-Wallis test }\end{array}$ & \\
\hline
\end{tabular}

\section{DISCUSSION}

Prevention of caries using pits and fissure sealants is highlighted in many studies $[1,8]$. The success of this measure lies in the adaptation, bonding of material and its retention in the tooth in question [9]. In present study, two types of resin based material that have been used as pits and fissure sealants and were later evaluated for their adaptability onto the tooth surface by using for SEM analysis. The results fail to reject the null hypothesis that indicated that there was no statically difference in the adaptation and bonding between the two sealant materials under with respect to the adaptation in various morphologies of pits and fissures.

The sealing ability of a restorative dental material is highly dependent on the way it adapts and retains [10]. In other words, adaptability of the sealants determines its retention in the tooth and resistance against dental caries [1]. Ideally, a fissure sealant should adapt well to the enamel and can bear masticatory forces and adheres to the walls of fissures.
A successful sealant is the one that is retained in the tooth and offers resistance against dental caries.

Resin based sealants are reported to exhibit excellent sealing ability $[11,12]$. However for better sealing Flowable Resin with adhesive was used for this study. Same as it was used in other studies when comparison of two or more Resins was done [11]. In the present study adhesive was applied prior to both type of sealant materials so that similar conditions can be applicable to both the materials.

Moreover, RMGIC showed less leakage than other types of conventional GIC [9, 13]. Moreover, RMGIC has been used with many standard materials for many other applications and remain successful as a suitable substitute. In the present study, RMGIC was compared with Flowable Resin which is the standard material for pits and fissure sealants.

Al-Jobair[14] and Loung[15] have also compared adaptability scores of sealant materials along with the microleakage scores but no statistical 
differences in the microleakage and adaptability scores of the two materials were observed.

Zakaria et al. [17] have compared three types of different sealant materials for their penetration into different types of fissure patterns. They observed statistical difference among different fissure morphologies and their adaptation with respect to different material used. They concluded that U- typed and V-typed fissure patterns were more penetrable and thus more adaptable than the I-typed and IK-typed.

In the present study, we compared the adaptability of sealant in different tooth morphologies of fissures which showed no statistical difference between the adaptability of the two materials irrespective of the fissure morphologies.

\section{Conclusions}

No significant difference was found between resin-based sealants and resin modified glass ionomerbased sealants for the adaptation in various tooth fissure patterns.

\section{Conflict of Interest} publication.

There are no conflicts of interest regarding this

\section{REFERENCES}

1. Nirwan M, Nigam AG, Marwah N, Nayak UA, Bansal A, Gahlot MS. A comparative evaluation of retention of pit and fissure sealant bonded using sixth-, seventh-, and eighth-generatio adhesives: An in vivo study. J Indian Soc Pedod Prev Dent. 2017;35(4):359-66.

1. Iyer RR, GopaPalakrishnapillai AC, Kalantharakath T. Comparisons of in vitro penetration and adaptation of moisture tolerant resin sealant and conventional resin sealant in different fissure types. Chin J Dent Res. 2013;16(2):127-36.

2. Kielbassa AM, Ulrich I, Schmidl R, Schüller C, Frank W, Werth VD. Resin infiltration of deproteinised natural occlusal subsurface lesions improves initial quality of fissure sealing. Int J Oral Sci. 2017;9(2):117-24.

3. Tamasas BI. The effects of different concentrations of ethyl alcohol as drying agent on pit and fissure sealant treatment. Tufts Univ School Dent Med; 2013.
4. Twetman S. The evidence base for professional and self-care prevention-caries, erosion and sensitivity. BMC Oral Health. 2015;15(Suppl 1):S1-8.

5. Moreira KMS, Kantovitz KR, Aguiar JPD, Borges AFS, Pascon FM, Puppin-Rontani RM. Impact of the intermediary layer on sealant retention: a randomized 24-month clinical trial. Clin Oral Investiq. 2017;21(5):1435-43.

6. Khanal S, Suprabha BS, Srikant N. Evaluation of microleakage and adaptability of glass ionomer and resin sealants with invasive and non-invasive technique. J Nepal Dent Assoc. 2010;11(1):4- 10.

7. Beiruti N, Frencken J, van't Hof M, van Palenstein Helderman WH. Caries-preventive effect of resinbased and glass ionomer sealants over time: a systematic review. Community Dent Oral Epidemiol. 2006;34(6):403-9.

8. Khan TN, Ali Abidi SY, Nawaz Khan KB, Ahmed S, Rehman Qazi FU, Saeed N. Micromechanical Intervention in Sandwich Restoration. J Coll Physicians Surg Pak 2015;25(11):781-4.

9. Wolf M, Küpper K, Reimann S, Bourauel C, Frentzen M. 3D analyses of interface voids in root canals filled with different sealer materials in combination with warm gutta-percha technique. Clin Oral Investiq. 2014;18(1):155-61.

10. Ahuja L, Jasuja P, Verma KG, Juneja S, Mathur A, Walia R. A comparative evaluation of sealing ability of new MTA based sealers with conventional resin based sealer: An in-vitro study. J Clin Diag Res. 2016;10(7):ZC76-9.

11. Al-Jobair A, Al-Hammad N, Alsadhan S, Salama F. Retention and caries-preventive effect of glass ionomer and resin-based sealants: An 18-monthrandomized clinical trial. Dent Mater J. 2017;36(5):654-61.

12. Nandana KL, Sankar AS, Kumar MM, Naveen K, Pranitha K, Manjula BS. Comparative evaluation of microleakage using three variables of glassionomer cement in primary and permanent teeth: An in vitro study. J Interdisc Dent. 2016;6(3):110 5.

13. Al-Jobair A. Scanning electron microscope analysis of sealant penetration and adaptation in contaminated fissures. J Indian Soc Pedod Prev Dent. 2013;31(3):169-74.

14. Luong E, Shayegan A. Assessment of microleakage of class $\mathrm{V}$ restored by resin composite and resin-modified glass ionomer and pit and fissure resin-based sealants following Er:YAG laser conditioning and acid etching: in vitro study. Clin Cosmet Investig Dent. 2018;10:83-92. 